\title{
A Robust Control Scheme to Enhance the Stability of a Grid-connected Large Scale Photovoltaic System
}

\author{
Gazi Md. Saeedul Islam, Student Member, IEEE, Ahmed Al-Durra, Member, IEEE, S. M. Muyeen, \\ Member, IEEE, and Junji Tamura, Senior Member, IEEE
}

\begin{abstract}
This paper presents a new robust control strategy to improve the steady-state and transient stabilities of a grid connected large scale photovoltaic (PV) system. The grid codes for PV system to provide dynamic grid support are getting stricter due to the substantial increase in the power generation from grid connected PV systems, in recent years. The proposed control scheme helps quick voltage recovery against different types of symmetrical and unsymmetrical faults and ensures a good DC link overvoltage protection. Detailed modeling for individual components of a grid connected large scale PV system are carried out using PSCAD/EMTDC to analyze the performance of the proposed strategy.
\end{abstract}

Index Terms-AC-DC power converters, current control, DCDC power converters, DC-link protection, distributed power generation, PSCAD, solar energy.

\section{INTRODUCTION}

$\mathrm{T}$ HE interest for electricity generation from renewable energy sources are growing significantly. This is mostly due to the environmental concerns regarding global warming caused by the conventional fossil fuels. Governments of different countries are adopting green energy friendly policies which are helping to boost up this growth. Solar energy is one of the major alternative energy sources. There has been considerable increase of electricity generation from solar energy conversion systems in recent years. From 2003 to 2009 , total installed capacity of PV plants has increased over 10 times (from 1.8 GW to $20.4 \mathrm{GW}$ ) [1]. Most of these PV plants are grid connected. Multi megawatt class PV plants are being installed in addition to the small residential applications. According to the current statistics, there are at least $150 \mathrm{PV}$ plants existing worldwide with capacity of $10 \mathrm{MW}$ or more [2]. The impact of these PV plants to the power systems is becoming significant. Therefore, shutdown of large PV plants may affect the stability of a power system adversely. Hence, new grid codes are being introduced for PV plants to operate more like conventional generators. For example, according to the recent German grid codes, PV plants connected to the high [3] and medium voltage [4] network must stay connected to

G. M. S. Islam, A. Al-Durra, and S. M. Muyeen are with the Department of Electrical Engineering, The Petroleum Institute, P. O. Box 2533, Abu Dhabi, UAE (e-mail: gislam@pi.ac.ae).

J. Tamura is with the Department of Electrical Engineering, Kitami Institute of Technology, Japan, 090-8507, Kitami, Japan. the grid to provide dynamic support during the fault conditions. Type 2 plants (generating plants other than synchronous generators) can be disconnected for a fault of 0 pu voltage dip for more than $150 \mathrm{~ms}$ and the voltage should recover to $0.9 \mathrm{pu}$ within $1.5 \mathrm{~s}$. From the beginning of 2011, $\mathrm{PV}$ plants are required to comply with this requirement [5].

Voltage source inverter (VSI) is the most important component for active power filters, static synchronous compensators (STATCOM), and grid integration of distributed generation. The main function of the VSI is to track the reference current accurately and regulate the DC link voltage and ac side voltage. The VSI must have fast transient response and robustness for low voltage ride through (LVRT) capability of a PV plant. Generally, three phase voltage source inverter control is twofold. The outer loop generates the reference currents by regulating DC link voltage and the output ac side voltage or real and reactive power, whereas the inner loop generates the switching pulses to track the reference currents. Conventional PI controllers [6]-[8] do not have fast transient performance as the controllers are unable to handle the nonlinear nature of the system. In modern control systems for power electronics, sliding mode control (SMC) has started to draw attention because of its large disturbance rejection capability and robustness. The controller does not require precise mathematical modeling. This makes it relatively insensitive to the parameter variations; though the knowledge of the range of parameter variation is needed to guarantee the stability of the system [9]. In [10], [11], sliding mode controller is used for the outer loop of the voltage source inverter of DG. The output of the SMC is passed through the PI controller which reduces the effectiveness of the SMC to the system. The inner current control loop is controlled by sliding mode control in [12]. But the implementation of the improved controller used for reducing the chattering issue is complex because of the use of higher order sliding surface.

In this paper, a $5 \mathrm{MW} \mathrm{PV} \mathrm{plant} \mathrm{is} \mathrm{modeled} \mathrm{to} \mathrm{study} \mathrm{the}$ transient performance of a new sliding mode based hybrid controller, keeping the realistic aspects of the total system under consideration. In section II, a detailed modeling of the large scale PV system is presented; section III describes the grid connection structure and control strategies for of the power conversion systems (PCS). Simulations are performed for different types of symmetrical and unsymmetrical faults using PSCAD/EMTDC [13] to study the performance of the 


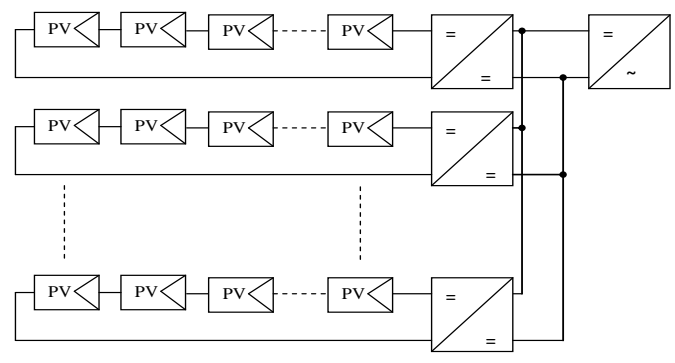

Fig. 1. Two stage PV System

proposed controller. The results are shown in section IV and conclusion is drawn based on the simulation results in section V.

\section{PV SYSTEM}

\section{A. PV Plant Modeling}

The modeling of a PV module is discussed in details in [14] and [15]. The aggregated model of a PV plant which is composed of a number of PV modules can be described as follows [16]

$$
\begin{aligned}
& I=N_{P} I_{P V}-N_{P} I_{0}\left[\exp \left(\frac{q\left(V+I R_{S}\right)}{N_{M} N_{S} a k T}\right)-1\right]-\frac{V+I R_{S} e q}{R_{P e q}} \\
& I_{0}=\frac{N_{P} I_{S C, n}+K_{I} \Delta T}{\exp \left(q\left(N_{M} V_{O C, n}+K_{V} \Delta T\right) / N_{M} N_{S} a k T\right)-1}
\end{aligned}
$$

where $N_{M}$ is the number of series connected modules in a string, $N_{p}$ is the number of strings connected in parallel; $R_{S e q}$ and $R_{P e q}$ are equivalent series and parallel resistance of the PV plant respectively. $N_{S}, I_{P V}$ and $I_{0}$ are the number of series connected cells, photo-current and reverse saturation current of each PV module respectively. $q$ is the electron charge $\left(1.602176 \times 10^{-19} \mathrm{C}\right), \quad k$ is the Boltzmann constant $\left(1.3806503 \times 10^{-23} \mathrm{~J} / \mathrm{K}\right)$ and $a$ is the ideality factor of the diode.

\section{B. PV Plant Topology}

The typical two stage PV plant with string topology is shown in Fig. 1. In this configuration, several PV panels are connected in series to form a string to scale up the output voltage of the plant. A DC-DC converter is connected to each string to extract maximum power from the PV string. All the strings are connected in parallel to a central inverter to obtain

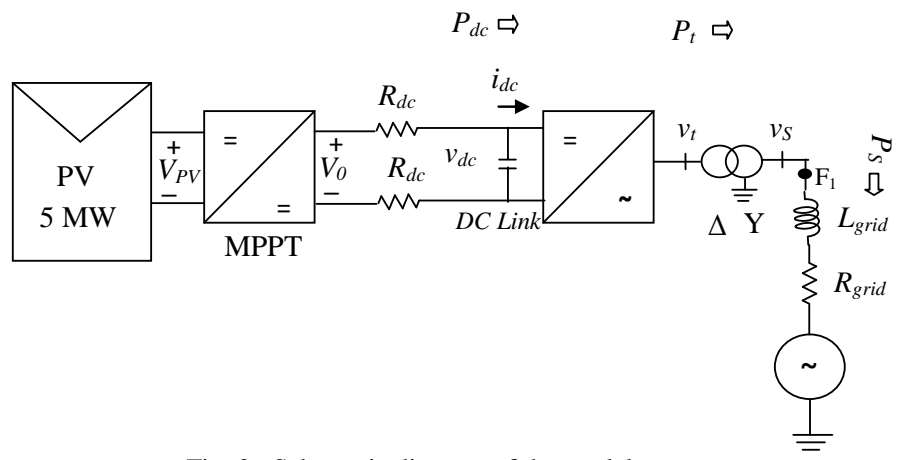

Fig. 2. Schematic diagram of the model system desired power from the plant. This topology is flexible as the plant capacity can be increased by adding new stings. It reduces the losses incurred because of the mismatch between the strings as each string is individually connected to DC-DC converter and the configuration is cost effective due to the reduction of number of inverters [17].

\section{SYSTEM DESCRIPTION AND CONTROL STRATEGIES}

\section{A. Grid Connection Structure}

The schematic diagram of the model system which is used for this study is shown in Fig. 2 where $v_{t}$ and $v_{S}$ are inverter output voltage and grid side rms voltage respectively. There is a 5 MW PV unit in the system connected to a DC-DC boost converter. In this paper, parameters of Kyocera KC200GT solar module are used to model the PV system [18]. The characteristic curve of a $5 \mathrm{MW}$ unit is shown in Fig. 3. The DC distribution system is modeled based on [19] and the parameters are used for TOP SOLAR XZ-K (AS) $1 \times 300 \mathrm{~mm}^{2}$ cable [20]. The system is then connected to a central three phase voltage source inverter through DC link capacitor to produce sinusoidal current and maintain a constant DC link voltage. Finally, a $\Delta$-Y (Y grounded) transformer is used to adopt the system with grid voltage. A Double circuit transmission line model is considered in this study for the sake of fault analysis. The parameters are given in Tables I and II.

\section{B. DC-DC Converter Control}

The DC-DC boost converter is used in PV system to step up the output voltage and extract maximum power by controlling the output voltage of the PV plant to a certain value for a particular temperature and irradiation. There is a number of maximum power point tracking (MPPT) techniques available. Different MPPT techniques are suitable for different applications. In this paper, fractional open circuit voltage technique is used for MPPT. The voltage of a PV module at maximum power point $\left(V_{M P P}\right)$ varies nearly linearly with its open circuit voltage $\left(V_{O C}\right)$ with the variation of weather condition (solar irradiation and temperature). This relationship can be expressed by

$$
V_{M P P}=K_{M P P} V_{O C}
$$

where $K_{M P P}$ is a proportionality constant. $K_{M P P}$ is found to be 0.8023 for KC200GT solar module. This value is validated for

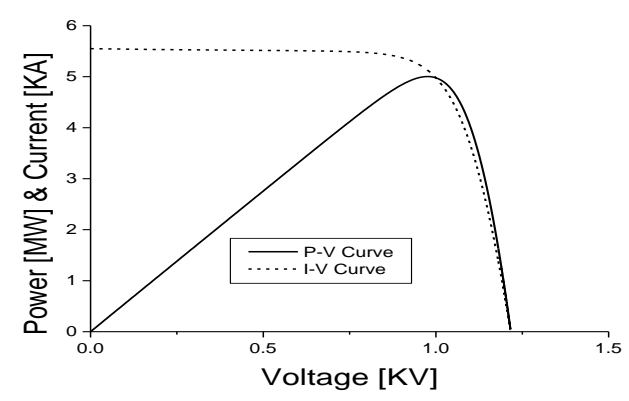

Fig. 3. I-V and P-V curve for $5 \mathrm{MW}$ unit 


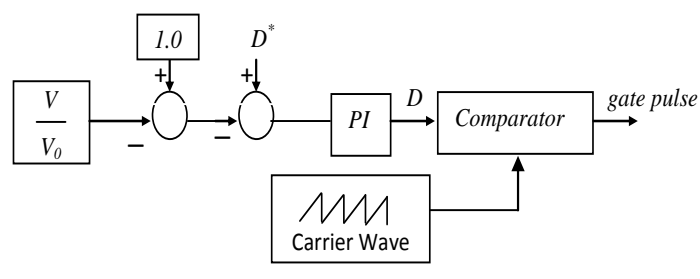

Fig. 4. Control block for boost converter

different irradiation and temperature $\left(25^{\circ} \mathrm{C}, 1000 \mathrm{~W} / \mathrm{m}^{2}\right.$ and $47^{0} \mathrm{C}, 800 \mathrm{~W} / \mathrm{m}^{2}$ ) from the datasheet available in [18]. The open circuit voltage can be measured using a pilot module under the same environmental condition [21]. This method helps to avoid the temporary disconnection of the PV system from the network. The voltage is scaled up to get the equivalent open circuit of the PV string. The reference duty ratio can be calculated by the following equation:

$$
D^{*}=1-\frac{N_{M} K_{M P P} V_{O C \_p i l o t}}{V_{0}}
$$

where $V_{O C_{-} \text {pilot }}$ is the open circuit voltage of the pilot module, $V_{0}$ is the output voltage of the boost converter. The DC-DC converter control strategy is shown in Fig. 4 where gate pulses are controlled to regulate the PV output voltage $\left(V_{P V}\right)$.

\section{Modeling and Control of Voltage Source Inverter}

\section{Outer Loop Control}

The power delivered at each stage of the system is shown in Fig. 2. The grid side power equations in space vector form are given by:

$$
\begin{aligned}
& P_{s}=\frac{3}{2}\left(v_{s d} i_{d}+v_{s q} i_{q}\right) \\
& Q_{s}=\frac{3}{2}\left(-v_{s d} i_{q}+v_{s q} i_{d}\right)
\end{aligned}
$$

where $v_{s d}, i_{d}$ and $v_{s q}, i_{q}$ are grid side $d$ and $q$ axis voltages and currents respectively. Using phase lock loop (PLL), $v_{s q}$ is set to zero. By keeping the terminal voltage constant the following relations can be found:

$$
\begin{aligned}
& P_{s} \propto i_{d} \\
& Q_{s} \propto i_{q}
\end{aligned}
$$

Hence $P_{S}$ and $Q_{S}$ can be controlled independently by controlling $i_{d}$ and $i_{q}$. Let us suppose transformer resistance and inductance are $R$ and $L$ respectively. $R$ is very small compare to $L$. Hence, power loss across $R$ is generally ignored. Ignoring the switching losses, the following relationship can be found during steady state:

$$
P_{d c} \approx P_{t} \approx P_{s}=P
$$

Again from dc side:

$$
P_{d c}=v_{d c} i_{d c}
$$

TABLE I

PARAMETERS FOR 2.5 MW PV PLANT

\begin{tabular}{|l|l|}
\hline Peak power & $5 \mathrm{MW}$ \\
\hline Voltage at maximum power & $973 \mathrm{~V}$ \\
\hline $\mathrm{N}_{\mathrm{S}}$ & 54 \\
\hline $\mathrm{N}_{\mathrm{M}}$ & 37 \\
\hline $\mathrm{N}_{\mathrm{P}}$ & 676 \\
\hline $\mathrm{R}_{\mathrm{Seq}}$ & $0.0121 \Omega$ \\
\hline $\mathrm{R}_{\mathrm{Peq}}$ & $22.74 \Omega$ \\
\hline $\mathrm{a}$ & 1.3 \\
\hline
\end{tabular}

* For $25^{\circ} \mathrm{C}$ and $1000 \mathrm{~W} / \mathrm{m}^{2}$

TABLE II

LINE PARAMETERS

\begin{tabular}{|l|l|}
\hline Length of DC lines & $1 \mathrm{~km}$ \\
\hline $\mathrm{R}_{\mathrm{DC}}$ & $2.41 \times 10^{-4} \Omega$ \\
\hline $\mathrm{V}_{\mathrm{dc}}$ & $1.2 \mathrm{kV}$ \\
\hline Transformer voltage ratio $(\Delta-\mathrm{Y})$ & $0.763 \mathrm{kV} / 22 \mathrm{KV}$ \\
\hline $\mathrm{R}_{\text {grid }}$ (for each line) & $9.68 \Omega$ \\
\hline $\mathrm{L}_{\text {grid }}$ (for each line) & $0.18487 \mathrm{H}$ \\
\hline
\end{tabular}

Hence,

$$
P_{d c} \approx P_{s} \propto i_{d}
$$

Therefore, by controlling the DC link voltage real power transfer $P_{S}$ can be controlled. Reactive power transfer $Q_{S}$ is directly proportional to the terminal voltage $V_{S}$. Hence from eqn. (8) the following relation can be found:

$$
v_{s} \propto i_{q}
$$

Thus $\mathrm{d}$ and $\mathrm{q}$ axis reference currents can be generated from DC link voltage and grid side terminal voltage respectively. To control the real and reactive power, the following firstorder sliding surfaces are considered for sliding mode operation [11]:

$$
\begin{aligned}
& S_{V d c}=e_{v d c}+K_{V d c} \frac{d e_{v d c}}{d t} \\
& S_{V S}=e_{v S}+K_{V S} \frac{d e_{v S}}{d t}
\end{aligned}
$$

where $e_{V d c}=v_{d c}{ }^{*}-v_{d c}$ and $e_{V S}=\left|v_{S}{ }^{*}\right|-\left|v_{S}\right| \cdot v_{d c}{ }^{*}$ and $v_{S}{ }^{*}$ are reference DC link voltage and reference grid side voltage respectively; $K_{V d c}, K_{V S}$ are sliding surface coefficients. The controlled states can be restricted on to the sliding surfaces by governing the conditions: $S_{V d c}=\dot{S}_{V d c}=0$ and $S_{V S}=\dot{S}_{V S}=0$ [10], [11]. This means:

$$
e_{v d c}=-K_{V d c} \frac{d e_{v d c}}{d t}
$$

$$
e_{v S}=-K_{V S} \frac{d e_{v S}}{d t}
$$


Hence, desired dynamic performance of the sliding surface can be achieved by proper choice of the sliding surface coefficients. To get the reference $d$ and $q$ axis currents, the following controller is chosen:

$$
\begin{aligned}
& i_{d}^{*}=e_{V d c}\left(K_{P_{-} V d c}+\frac{K_{I_{L} V d c}}{s}\right)+\left|S_{V d c}\right| \cdot K_{S_{-} V d c} \cdot \operatorname{sgn}\left(S_{V d c}\right) \\
& i_{q}^{*}=e_{V S}\left(K_{P_{-} V S}+\frac{K_{I_{-} V S}}{s}\right)+\left|S_{V S}\right| \cdot K_{S_{-} V S} \cdot \operatorname{sgn}\left(S_{V S}\right)
\end{aligned}
$$

where $K_{P_{-} V d c}, K_{I_{-} V d c}$, and $K_{P_{-} V S}, K_{I_{-} V S}$ are the gains of the PI controllers; $K_{S_{-} V d c}$ and $K_{S_{-} V S}$ are sliding mode controller gains. Figure 5 shows the control structure and three phase view of the grid connected inverter. The outer loop sliding mode controllers help to reject large voltage disturbances. To further improve the performance, magnitudes of the sliding surfaces are used as sliding mode controller gains (Fig. 5(b)); they work like adaptive gains which give large values if there is any disturbance and smaller gains during steady state condition. Hence chattering during the steady state condition is also minimized. The PI controllers control the settling time and overshoot to some extent.

\section{Inner Loop Control}

From Fig. 5(a) the following state space equations can be found:

$$
\begin{aligned}
& L \frac{d i_{a}}{d t}=-R i_{a}+v_{t a}-v_{s a} \\
& L \frac{d i_{b}}{d t}=-R i_{b}+v_{t b}-v_{s b} \\
& L \frac{d i_{c}}{d t}=-R i_{c}+v_{t c}-v_{s c}
\end{aligned}
$$

Voltage drop across the resistance is very small and generally ignored. When the upper switch is conducting and the lower switch is off, for each leg the following relationship can be obtained:

$$
L \frac{d i_{i}}{d t}=\frac{1}{2} v_{d c}-v_{s i}>0 \quad i=a, b, c
$$

Similarly when the upper switch is off and lower switch is conducting:

$$
L \frac{d i_{i}}{d t}=-\frac{1}{2} v_{d c}-v_{s i}<0 \quad i=a, b, c
$$

From eqn. (22) and (23) it is clear that the current slope is positive when $\mathrm{v}_{\mathrm{t}}=\mathrm{v}_{\mathrm{dc}} / 2$ and negative for $\mathrm{v}_{\mathrm{t}}=-\mathrm{v}_{\mathrm{dc}} / 2$. Therefore, the following sliding mode control laws are considered:

$$
v_{t i}=K_{i} \operatorname{sign}\left(S_{i}\right) \frac{v_{d c}}{2} \quad i=a, b, c
$$

where $S_{i}=i_{i}{ }^{*}-i_{i}$; this implies:

$$
\begin{array}{ll}
L \frac{d i_{i}}{d t}=K_{i} \operatorname{sign}\left(S_{i}\right) \frac{v_{d c}}{2}-v_{s i}>0 & i=a, b, c \\
\dot{S}_{i}=\frac{d i_{i}^{*}}{d t}-K_{i} \operatorname{sign}\left(S_{i}\right) \frac{v_{d c}}{2 L}+\frac{v_{s i}}{L} & i=a, b, c
\end{array}
$$

The reaching condition for the sliding surface is $S_{i} \dot{S}_{i}<0$. Therefore, the value of $K_{i}$ should be:

$$
K_{i}>2\left[L \frac{d i_{i}^{*}}{d t}+v_{s i}\right] / v_{d c} \quad i=a, b, c
$$

The switching laws are defined as follows:

$$
\begin{aligned}
& U_{i}>0 \text {; Upper switch is On and lower switch is Off } \\
& U_{i}<0 \text {; Upper switch is Off and lower switch is On }
\end{aligned}
$$

where $U_{i}=K_{i} \operatorname{sign}\left(S_{i}\right)$. With the above mentioned current control strategy, the more the system moves towards the steady-state the higher the frequency of the gate signals becomes. And finally the switching losses become so high that power collapses because of the imbalance between power of the two sides of the inverter and consequently voltages collapse. In order to avoid that, hysteresis buffer is added in the inner sliding mode control loop.

\section{SimUlation RESUltS}

Simulations are performed for standard test condition (STC) $\left(1000 \mathrm{~W} / \mathrm{m}^{2}\right.$ and $\left.25^{\circ} \mathrm{C}\right)$ using power system simulator PSCAD/EMTDC. Simulation time step is $20 \mu \mathrm{s}$ and all the simulations are carried out for $3 \mathrm{~s}$.

Different symmetrical and unsymmetrical faults (3LG, 2LG, 1LG, L-L) are considered in one of the double transmission line at F1 location shown in Fig. 2. The faults

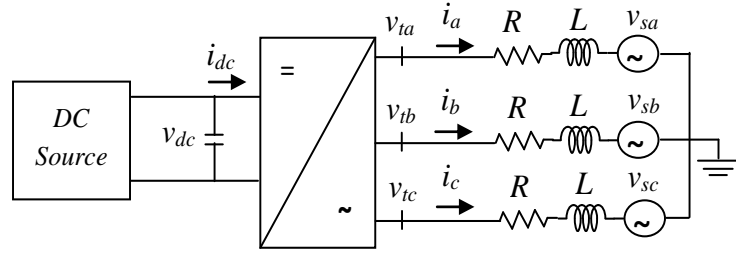

(a)

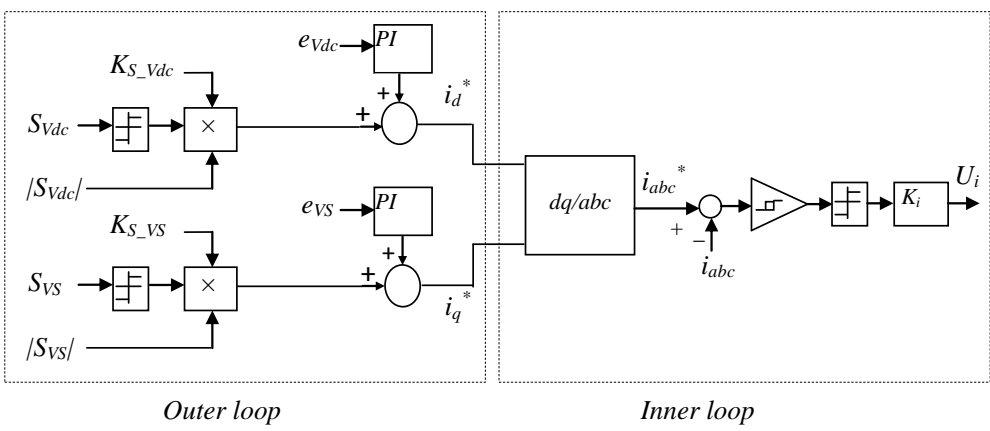

(b)

Fig. 5. Grid connected voltage source converter. (a) Three-phase view. (b) Proposed control structure 


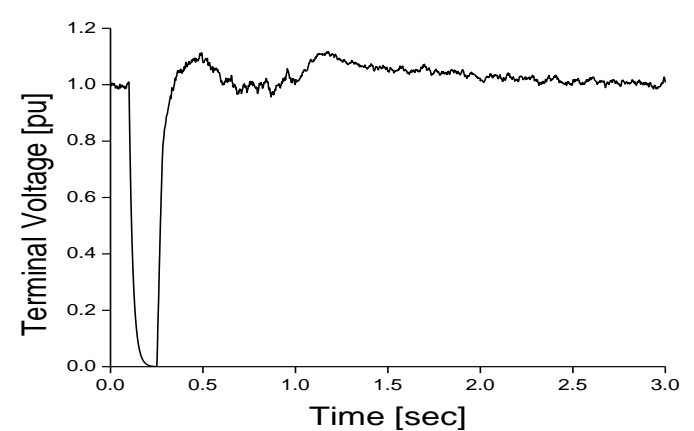

Fig. 6. Grid side voltage (3LG fault)

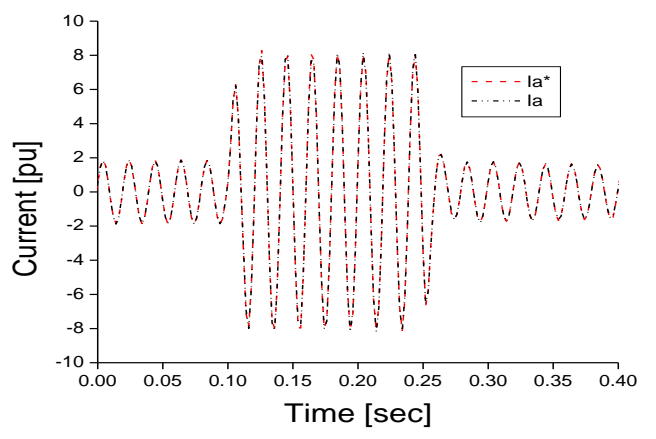

Fig. 7. Phase-a current (3LG fault)

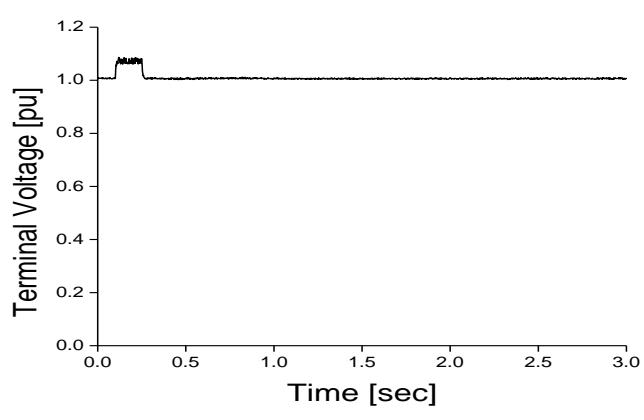

Fig. 8. DC link voltage (3LG fault)

occurred at $0.1 \mathrm{~s}$ and cleared at $0.3 \mathrm{~s}$; the breakers operated at $0.25 \mathrm{~s}$ and reclosed at $1 \mathrm{~s}$.

In order to avoid large integral value during the fault conditions, the integral controller used for $e_{V S}$ (shown in fig. $5(\mathrm{~b}))$ resets if the terminal voltage $v_{S}$ goes below $0.58 \mathrm{pu}$. This helps to reduce the voltage overshoot after the fault is cleared. Fig. 6 shows the grid side voltage for 3 LG fault. Clearly the voltage is recovered to its nominal value before $0.35 \mathrm{~s}$. This is well within the time limit mentioned in the grid code in Sect.I.

Another important issue for LVRT is DC link voltage regulation. If the current controller is not fast enough (for example PI controller), the DC link voltage drops during the fault condition and there is overshoot after the fault is cleared. This could easily damage the power electronic devices used in the system. Therefore, DC link protection is required in order to avoid the shutdown of the system during the fault conditions; this requires additional expense for voltage protection circuit. Figures 7 and 8 show the phase-a current

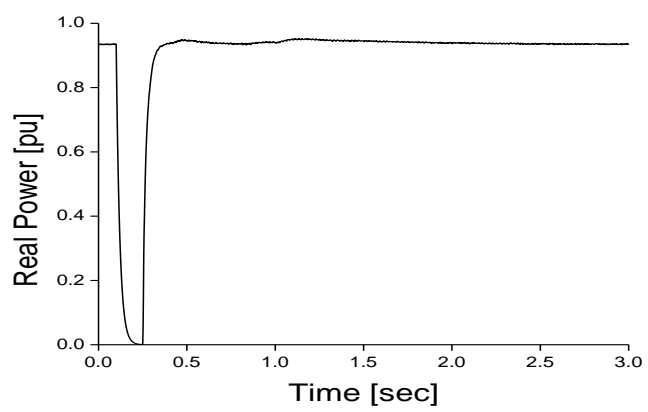

Fig. 9. Real power delivered to the grid (3LG fault)

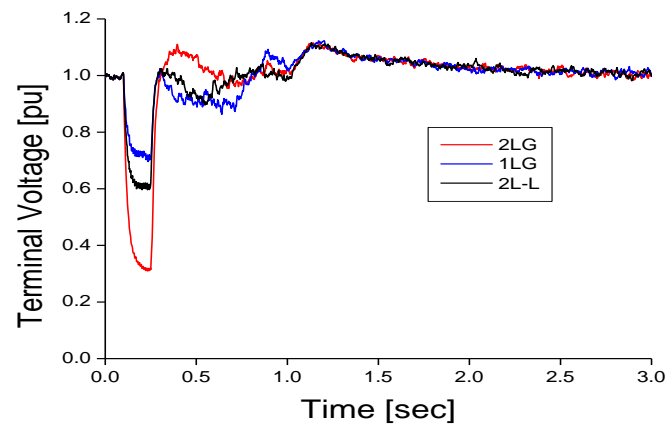

Fig. 10. Grid side voltage (2LG, 1LG, LL faults)

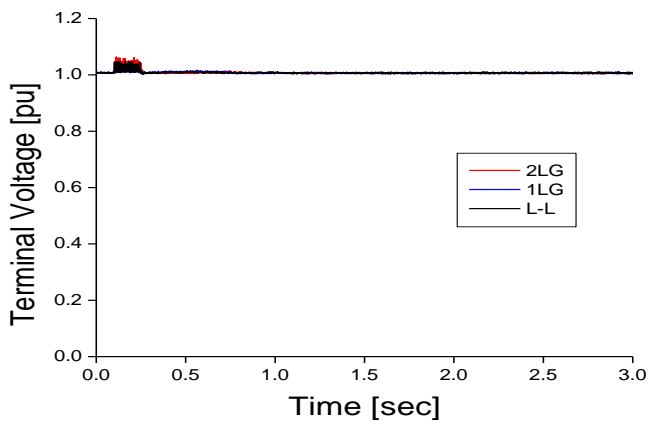

Fig. 11. DC link voltage (2LG, 1LG, LL faults)

and DC link voltage for 3 LG fault; with the proposed controller the current can accurately track the reference current during the fault condition. There is no voltage dip for DC link voltage; and the overshoot is less than $110 \%$. Hence, the proposed control strategy itself gives a very good DC link under voltage and over voltage protection which is required for providing dynamic grid support during grid faults. The real power delivered to the grid for $3 \mathrm{LG}$ fault is also shown in fig. 9.

Similarly, grid side voltage and DC link voltage for $2 \mathrm{LG}$, 1LG, and L-L faults are shown in Fig. 10, and 11 respectively. The grid side voltage recovery and overshoot is well within the limit for low voltage ride through for all types of faults; the DC link voltage overshoot is well below $110 \%$.

\section{CONCLUSION}

In this paper, a detailed modeling of a grid connected large scale PV system has been presented and a new control scheme 
has been proposed to improve the low voltage ride through capability of the system. It is found that with the proposed control strategy, the grid side voltage recovery is very fast and DC link overvoltage is very small which is required to avoid shutdown of the system during the fault conditions. The system even works well in steady-state conditions, though the results are not shown here. Hence the controller can be implemented to enhance the transient stability of the PV system.

\section{REFERENCES}

[1] Trends in photovoltaic applications- Survey report of selected IEA countries between 1992 and 2009. [Online]. Available: http://www.ieapvps.org/

[2] Large-scale photovoltaic power plants ranking. [Online]. Available: http://www.pvresources.com/en/top50pv.php.

[3] "Transmission code 2007 - network and system rules of the German transmission system operators," Verband der Netzbetreiber (VDN), Aug. 2007.

[4] "Technical guideline - generating plants connected to the mediumvoltage network," Bundesverband der Energie- und Wasserwirtschaft,BDEW, Jun. 2008.

[5] E. Troester, "New German grid codes for connecting PV systems to the medium voltage power grid," $2^{\text {nd }}$ International Workshop on Concentrating Photovoltaic Power Plants: Optical Design, Production, Grid Connection, Darmstadt, Germany, Mar. 2009.

[6] A. Khalifa, and E. El-Saadany, "Control of three phase grid connected photovoltaic power systems," 14th International Conference on Harmonics and Quality of Power (ICHQP), Nov. 2010.

[7] M. Kazmierkowski, R. Krishnan, and F. Blaabjerg, Control in Power Electronics: Selected Problems. New York: Academic Press, 2002.

[8] L. Norum, W. Sulkowski, and L. Aga, "Compact realisation of PWMVS1 current controller for PMSM drive application using low cost standard microcontroller," in Proc. IEEE 23rd Аnиu. Power Electron. Spec. Conf. (PESC), 1992, vol. 1, pp. 680-685.

[9] V. Raviraj, and P. Sen, "Comparative study of proportional-integral, sliding mode, and fuzzy logic controllers for power converters," IEEE Trans. Ind. Electron., vol. 33, no. 2, pp. 518-524, Mar./Apr. 1997.

[10] Y. Mohamed, and E. El-Saadany, "A control of grid-connected PWM voltage source inverters to mitigate fast voltage disturbances," IEEE Trans. Power Syst., vol. 24, no. 1, Feb. 2009.

[11] Y. Mohamed, and E. El-Saadany, "A control scheme for PWM voltagesource distributed-generation inverters for fast load-voltage regulation and effective mitigation of unbalanced voltage disturbances," IEEE Trans. Ind. Electron., vol. 55, no. 5, May 2008.

[12] L. Jianing, S. Shiping, L. Guiying, Q. Zhiqing, and D. Hang, "The sliding mode control method of grid-connected inverter applied to threephase intermittent power supply," in Proc. 29th Chinese Control Conference (CCC), Jul. 2010

[13] "PSCAD/EMTDC user's guide," Manitoba HVDC Research Center, 2005.

[14] M. G. Villalva, J. R. Gazoli, and E. R. Filho, "Comprehensive approach to modeling and simulation of photovoltaic arrays," IEEE Trans. Power Electron., Vol. 24, no. 5, pp. 1198-1208, May 2009.

[15] G. Vachtsevanos, and K. Kalaitzakis, "A hybrid photovoltaic simulator for utility interactive studies," IEEE Trans. Energy Conv., Vol. EC-2, no. 2, Jun. 1987.

[16] G. Islam, A. Al-Durra, S.M. Muyeen, and J. Tamura, "Low voltage ride through capability enhancement of grid connected large scale photovoltaic system," accepted in Proc. IEEE Annu. Conf. Ind. Electron. Soc. (IECON'11), Nov. 2011.

[17] M. Brenna, R. Faranda, and S. Leva, "Dynamic analysis of a new network topology for high power grid connected PV systems," Power and Energy Society General Meeting, Minneapolis, Jul. 2010.

[18] Kyocera KC200GT- high efficiency multicrystal photovoltaic module datasheet. [Online]. http://www.kyocera.com.sg/products/solar/pdf/kc200gt.pdf

[19] M. R. Starke, "DC distribution with fuel cells as distributed energy resources," Ph.D. dissertation, Dept. Electric. Eng., Univ. Tennessee, Knoxville, 2009.
[20] Cables for photovoltaic solar installations. [Online]. Available: www.elesis.gr/php/download.php?file=solar_cables_presentation.pdf

[21] G.W. Hart, H. M. Branz, and C. H. Cox, "Experimental tests of openloop maximum-power-point tracking techniques," Solar Cells, vol. 13, pp. 185-195, Dec. 1984.

\section{BIOGRAPHIES}

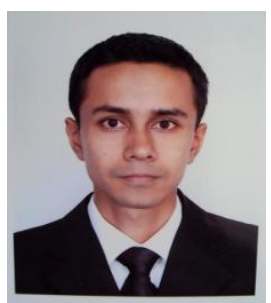

Gazi Md. Saeedul Islam (S'11) received his B.Sc. degree in Electrical and Electronic Engineering from Islamic University of Technology (IUT), Dhaka, Bangladesh, in 2006. He was with Grameenphone Ltd. as a System Engineer in Bangladesh. Currently he is pursuing his M.Sc. at the Petroleum Institute (PI), Abu Dhabi, UAE. His research interests include grid integration of distributed generation, controls in power electronics, power system stability and control. Mr. Islam is a student member of IEEE.

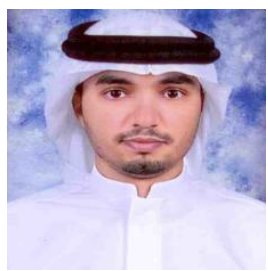

Dr. Ahmed Al-Durra (M'07) received the B.S., M.S., and $\mathrm{PhD}$ in Electrical and Computer Engineering from the Ohio State University in 2005, 2007, and 2010, respectively. For his M. Sc. degree, he investigated the application of several nonlinear control techniques on automotive traction PEM fuel cell systems. He conducted his $\mathrm{PhD}$ research at the Center for Automotive Research in the Ohio State University. His PhD work was on the applications of modern estimation and control theories to automotive propulsion systems." At the present, he is working as Assistant Professor in Electrical Engineering Department at the Petroleum Institute, Abu Dhabi. His research interests are application of estimation and control theory in power system stability and control, energy storage system (ESS), and renewable energy. Dr. Ahmed is a member of IEEE, and ASME.

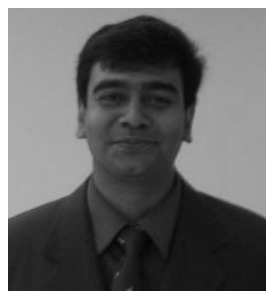

Dr. S. M. Muyeen (M'08) received his B.Sc. Eng. Degree from Rajshahi University of Engineering and Technology (RUET), Bangladesh formerly known as Rajshahi Institute of Technology, in 2000 and M. Sc. Eng. and Dr. Eng. Degrees from Kitami Institute of Technology, Japan, in 2005 and 2008 respectively, all in Electrical and Electronic Engineering. His $\mathrm{PhD}$ research work focused on wind farm stabilization from the viewpoint of LVRT and frequency fluctuation. After completing his Ph.D. program he worked as a Postdoctoral Research Fellow under the versatile banner of Japan Society for the Promotion of Science (JSPS) from 2008-2010 at the Kitami Institute of Technology, Japan. At the present, he is working as Assistant Professor in Electrical Engineering Department at the Petroleum Institute, Abu Dhabi. His research interests are power system stability and control, electrical machine, FACTS, energy storage system (ESS), Renewable Energy, and HVDC system. He has published over 70 international papers. He has published three books and few book chapters as well. He has also served as an Editor of the book entitled "Wind Power" in 2010. Dr. Muyeen is the member of IEEJ, and IEEE.

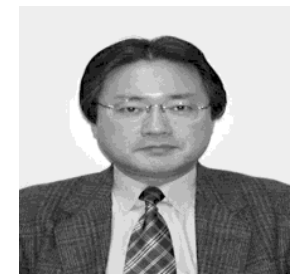

Dr. Junji Tamura (SM'92) received the B.Sc. Eng. Degree from Muroran Institute of Technology, Muroran, Japan, in 1979 and the M.Sc. Eng. and Dr. Eng. Degrees from Hokkaido University, Sapporo, Japan, in 1981 and 1984, respectively, all in electrical engineering. In 1984, he became a lecturer and in 1986, an associate professor at the Kitami Institute of Technology, Kitami, Japan. Currently he is a professor at the Kitami Institute of Technology. 